\title{
Thrombotic responses to coronary stents, bioresorbable scaffolds and the Kounis hypersensitivity-associated acute thrombotic syndrome
}

\author{
Nicholas G. Kounis, Ioanna Koniari, Anastasios Roumeliotis, Grigorios Tsigas, George Soufras, Nicholas \\ Grapsas, Periklis Davlouros, George Hahalis
}

Department of Cardiology, University of Patras Medical School, Patras, Rion, Achaia, Greece

Contributions: (I) Conception and design: All authors; (II) Administrative support: None; (III) Provision of study materials or patients: All authors; (IV) Collection and assembly of data: All authors; (V) Data analysis and interpretation: All authors; (VI) Manuscript writing: All authors; (VII) Final approval of manuscript: All authors.

Correspondence to: Nicholas G. Kounis. Queen Olgas Square, 7 Aratou Street, Patras, Achaia, Greece. Email: ngkounis@otenet.gr.

\begin{abstract}
Percutaneous transluminal coronary angioplasty with coronary stent implantation is a lifesaving medical procedure that has become, nowadays, the most frequent performed therapeutic procedure in medicine. Plain balloon angioplasty, bare metal stents, first and second generation drug-eluting stents, bioresorbable and bioabsorbable scaffolds have offered diachronically a great advance against coronary artery disease and have enriched our medical armamentarium. Stented areas constitute vulnerable sites for endothelial damage, endothelial dysfunction, flow turbulence, hemorheologic changes, platelet dysfunction, coagulation changes and fibrinolytic disturbances. Implant surface attracts several proteins such as albumin, fibronectin, fibrinogen, and complement that lead to complement system activation. Macrophages recognize the implant as foreign substance due to protein adsorption and its continuous presence results in macrophage differentiation and fusion into foreign body giant cells. Polymer coating, stent metallic platforms and the released drugs can act as strong antigenic complex that apply continuous, repetitive, persistent and chronic hypersensitivity irritation to the coronary intima. The concomitant administration of oral antiplatelet drugs and environmental exposures can induce hypersensitivity inflammation. A class of platelets, activated via high-affinity and low-affinity IgE hypersensitivity receptors FC $\gamma$ RI, FC $\gamma$ RII, FCeRI and FCeRII, can induce Kounis hypersensitivity-associated thrombotic syndrome inside the stented coronaries. Type III variant of this syndrome is diagnosed when coronary artery stent thrombosis is associated with thrombus infiltrated by eosinophils or mast cells and/or when coronary intima, media and adventitia adjacent to stent, is infiltrated by eosinophils or mast cells. Careful history of hypersensitivity reactions to all implanted materials and concomitant drugs with monitoring of inflammatory mediators as well as lymphocyte transformation studies to detect hypersensitivity must be undertaken in order to avoid disastrous consequences. Food and Drug Administration recommendations for coronary stent implantation should be applied also to bioresorbable scaffolds. Further studies with inert and non-allergenic implants are necessary.
\end{abstract}

Keywords: Bioabsorbable stents; bioresorbable stents; foreign body reaction; Kounis syndrome; stent hypersensitivity; stent thrombosis

Submitted Jul 23, 2016. Accepted for publication Feb 08, 2017.

doi: $10.21037 /$ jtd.2017.03.134

View this article at: http://dx.doi.org/10.21037/jtd.2017.03.134 


\section{Introduction}

Percutaneous transluminal coronary angioplasty with coronary stent implantation is a life saving medical procedure that has become, nowadays, the most frequent performed therapeutic procedure in medicine (1).

The initial plain balloon angioplasty performed in September 1977 by Andreas Gruentzig (2) is a plain dilatation of coronary artery but has many disadvantages such as restenosis due to elastic recoil, constrictive remodeling, neointimal hyperplasia and the risk of acute vessel closure due to uncovered dissection (3). Following this initial procedure, that is occasionally used today, and in an effort to provide solution to acute vessel occlusion by sealing the dissection flaps and preventing recoil, a new technology, the deployment of coronary stents has been implemented. There are three kinds of stents used today, the bare metal stents, the first and the second generation drug-eluting stents and the bioresorbable-bioabsorbable stents.

The bare metal stents consist of a $316 \mathrm{~L}$ stainless steel platform containing nickel, chromium, titanium, manganese, and molybdenum (4). This metal platform, while can prevent the late luminal enlargement and further induce the beneficial vascular remodeling, fails to prevent restenosis that remains a crucial problem due to neointimal hyperplasia.

The first and the second generation drug eluting stents have been developed in an effort to prevent vessel restenosis (5).

The first generation drug eluting stents still have the stainless steel platform covered with durable polymer coating that serves as drug carrier and permits controlled drug release. The released drugs have antiproliferative properties and include the sirolimus substance that inhibits the mammalian target of rapamycin and prevents reendothelialization and the antineoplastic agent paclitaxel, thus avoiding stent restenosis (6). The durable polymers used in first generation drug eluting stents have been associated with mechanical complications such as polymer delamination and "webbed" polymer surface leading to stent expansion issues and non-uniform coating resulting in erratic drug distribution (7). The sirolimus and paclitaxel eluting stents, have been approved in the United States in 2003 and 2004 respectively, but are no longer available in the United States and Europe due to superiority of second generation stents.

The second generation drug eluting stents dispose also stainless steel platform but with cobalt or platinum alloy and a biocompatible durable or biodegradable polymer combined with the antiproliferative drug everolimus or zotarolimus (8). These second generation, drug eluting stents unfortunately, carry the commercial misleading term cobalt-chromium and platinum-chromium stents while have platforms of stainless steel which contain also nickel together with other metals. Indeed, the XIENCE everolimus stent contains approximately $10 \%$ nickel and the Endeavor zotarolimus stent 35\% nickel respectively, much more than the first generation drug eluting stents (9).

Despite that drug eluting stents have significantly reduced in-stent restenosis and target lesion revascularization rates compared with bare metal stents, a very dangerous and lethal side effect has emerged with these stents that is acute, subacute, late and especially very late stent thrombosis. While drug eluting stents have halved the need for repeat intervention compared with bare metal stents (10) and have reduced stent thrombosis to $0.5-1 \%$ yearly (11), these results could be higher in the real world. In a study (12) concerning 5,842 patients treated with primary percutaneous coronary intervention, 201 (3.5\%) developed a definite early stent thrombosis. Of these, 97 (1.7\%) had acute stent thromboses and $104(1.8 \%)$ had subacute stent thromboses. In another study concerning 314 patients with drug eluding stent implantation (13) who were followed for $20 \pm 6.7$ months, the incidence of stent thrombosis was $4.4 \%$ (incidence density 2.7 cases/100 patients-years) and the case fatality $36 \%$. Whether stent thrombosis is a time limited event is not known, therefore stent thrombosis might increase if it continues over the time.

The biodegradable stents combine bioresorbablebioabsorbable stent technology that has been developed in an effort to reduce or even to abolish late/very late stent thrombotic risk (14). This technology allows positive remodeling, enables restoration normal vasomotor tone while simultaneously reducing the trigger for persistent inflammation and facilitating further interventions by percutaneous or surgical means (15). With bioresorbable technology, all stent components (drug, polymer, or scaffold) are absorbed and none are left behind, while with bioabsorbable stents only the drug and the polymer are absorbed and leave behind a bare metal scaffold (16).

Therefore, understanding the mechanisms, the causes and the manners of prevention of dangerous stent thrombosis by developing new stent scaffolds is of paramount importance in clinical practice.

\section{Why stents are prone to thrombosis}

The development of thrombus inside the stent lumen is 
Pathophysiology of stent thrombosis and the Kounis thrombotic syndrome

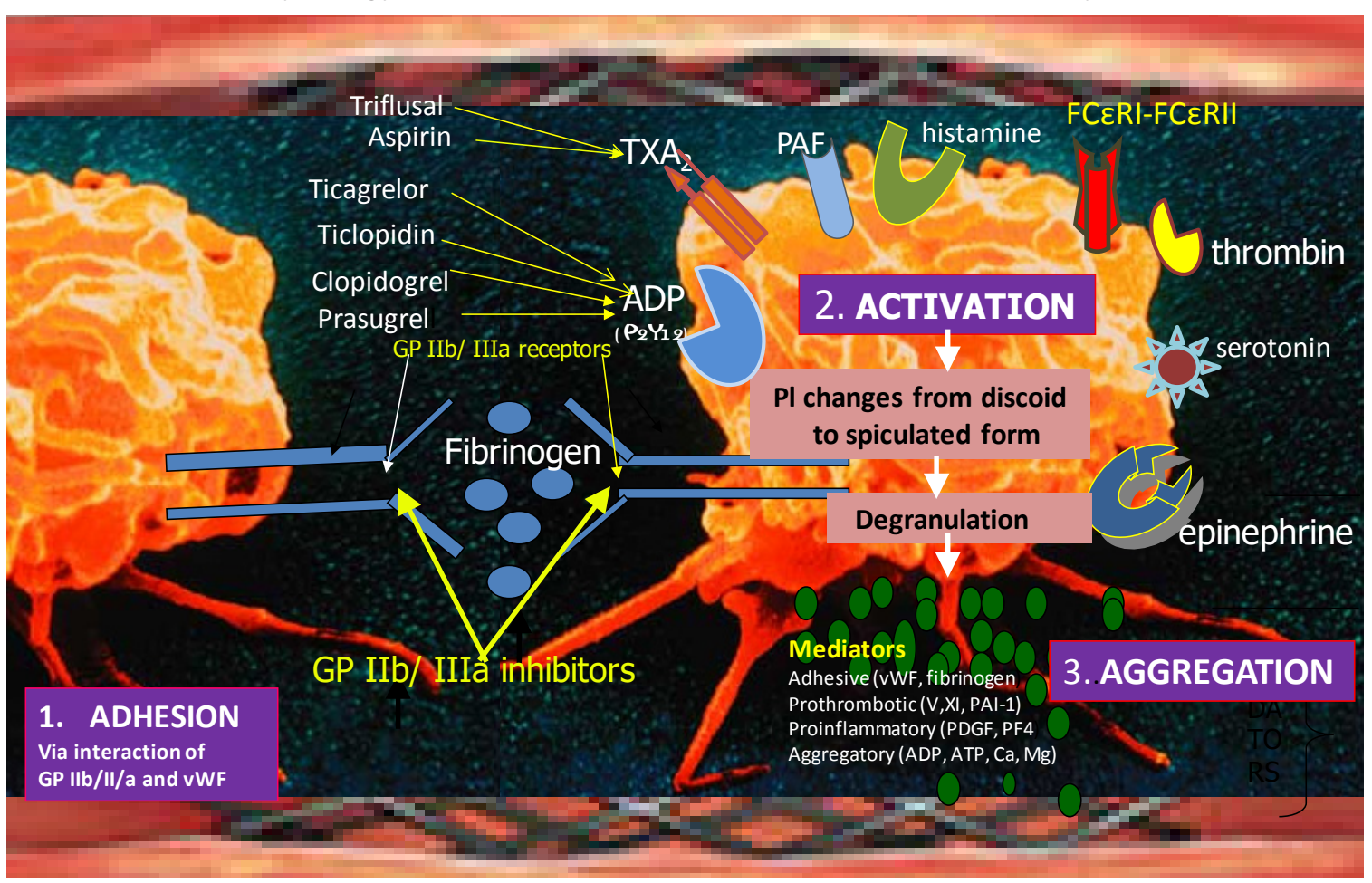

Figure 1 Platelet adhesion, activation and aggregation via TXA2, ADP (P2Y12), GP IIb/ IIIa receptors leading to stent thrombosis and via PAF, histamine, high and low affinity FCeRI-FCeRII receptors leading to type III variant of Kounis hypersensitivity-associated thrombotic syndrome.

the result of platelet adhesion, platelet activation followed by platelet aggregation (17). The stented areas constitute sites of endothelial damage, endothelial dysfunction, flow turbulence, hemorheologic changes, platelet dysfunction, coagulation changes and fibrinolytic disturbances at least until re-endothelialization will have been completed.

Platelet adhesion takes place shortly after an endothelial damage occurs or an atherosclerotic plaque has ruptured, eroded, or become disrupted and it is mainly mediated via the platelet glycoprotein IIb receptor through its interaction with von Willebrand factor.

Platelet activation involves several interrelated processes. First, the three-dimensional shape of the platelet changes from a smooth discoid appearance into a speculated form, greatly increasing the surface area of the platelet membrane where thrombin is generated. Platelet surface membrane contains glycoprotein IIb/IIIa receptors, receptors for thromboxane, adenosine diphosphate, thrombin, serotonin, epinephrine, histamine and platelet activating factor (18). The latter is released from mast cells and other interrelated and interacting inflammatory cells including platelets and is an important mediator of hypersensitivity inflammation and anaphylaxis. It induces also platelet aggregation (19), releases histamine, serotonin, $\mathrm{PF}-4$ both in vitro and during anaphylaxis in the rabbit $(20,21)$. A class of platelets with high and low affinity FC $\gamma$ RI, FC $\gamma$ RII, FCeRI and FCeRII $\mathrm{IgE}$ receptors in their surface (22) are involved in the activation cascade and are activated during hypersensitivity responses. During their activation, platelets secrete proinflammatory (platelet factor 4 , platelet derived growth factor, CD154), pro thrombotic (factor V, factor XI, PAI-1), adhesive (thrombospondin, fibrinogen, p-selectin, von Willbrand factor) and chemotactic (ADP, ATP, serotonin, histamine, calcium, magnesium) mediators that propagate, amplify and sustain the thrombotic process (Figure 1).

Finally, all above processes with their actions and interactions occurring during platelet activation lead to a conformational change in the GP IIb/IIIa receptor, converting the receptor into a form that can bind fibrinogen and link with other platelets thus resulting in platelet 
aggregation.

It must be pointed out that platelet activation in human plasma induced by thrombin or adenosine diphosphate can be significantly inhibited by $\mathrm{H} 1$-antihistamine dithiaden as it has been shown experimentally $(23,24)$.

Aspirin and triflusal that inhibit the action of thromboxane A2 by their effect on cyclooxygenase 1, ticagrelor, prasugrel, clopidogrel, and ticlopidine that prevent the binding of adenosine diphosphate to its receptor $\mathrm{P} 2 \mathrm{Y}_{12}$ and antithrombins such as unfractionated or low molecular-weight heparin, hirudin and bivalirudin that interfere with thrombin-induced platelet activation and coagulation are used clinically as counteracting measures.

Therefore, inflammation and especially hypersensitivity inflammation plays an important role in the stent thrombotic cascade and needs counteraction.

\section{Causes of stent thrombosis}

Currently, stent thrombosis is regarded as multifactorial process involving mechanical, technical and biological factors including strut fracture, late strut malapposition, loss of intimal coverage of the strut due to erosion, neoatherosclerosis, suboptimal stent insertion, stent length, vessel calcification, multivessel disease, totally occluded lesion at baseline, post-procedural TIMI flow $<3$, insulin dependent diabetes, advanced age, low ejection fraction, flow disturbances, changes in shear stress, withdrawal of clopidogrel and/or aspirin, clopidogrel resistance, brachytherapy and delayed endothelialization (6). One can wonder if the above factors are dependent on inflammation and specifically to hypersensitivity inflammation.

Thus far, infiltration of various interrelated and interacting inflammatory cells, including eosinophils, macrophages, $\mathrm{T}$ cells, and mast cells that point towards hypersensitivity inflammation, has been found in all clinical reports and reported pathologic findings in all patients who have died from stent thrombosis, and in all animal studies and experiments.

Covering polymers, metals and eluted drugs constitute important class of substances that can act as antigens. Apart from the well-known significance of nickel, chromium, and cobalt in inducing skin hypersensitivity, other metals such as aluminum, beryllium, copper, gold, iridium, mercury, palladium, platinum, rhodium, and titanium are emerging as human body sensitizers. In the US nickel, chromium and cobalt induce allergic skin reactions in about $14 \%$, $4 \%$, and $9 \%$ while in Europe in about 20\%, 4\%, and $7 \%$, respectively $(25)$.

Consequently, all stent components, namely, polymer coating, stent platforms with their metals and the released drugs can act as strong antigens that apply continuous, repetitive, persistent and chronic hypersensitivity irritation to the coronary intima. An "antigenic complex" of polymers, nickel alloys, eluted drugs, comes in touch with the delicate coronary intima. This complex, together with concomitant administration of oral antiplatelet drugs and environmental exposures can induce hypersensitivity inflammation and stent thrombosis.

The described three phases of hypersensitivity inflammation (26), the early phase which lasts for minutes, the late phase which lasts from $2 \mathrm{~h}$ to 2 days and the chronic phase that follows continuous, persistent or repetitive allergen exposure and lasts as long as the allergen is present, seem to correspond temporally with early [acute $<24 \mathrm{~h}$ and subacute (1-30 days), late (>30 days) and very late (>12 months)] stent thrombosis (27). This supports our view that definite or confirmed (symptoms suggestive of an acute coronary syndrome with angiographic or pathologic confirmation), probable (unexplained death within 30 days or target vessel myocardial infarction without angiographic confirmation) and possible stent thrombosis (any unexplained death after 30 days) are mainly the result of hypersensitivity inflammation.

Therefore, continuing efforts should be applied towards avoiding, preventing and treating hypersensitivity inflammation that could lead to dangerous stent thrombosis.

\section{Kounis hypersensitivity-associated thrombotic syndrome and stent thrombosis}

Kounis syndrome was described more than 25 years ago (28) and has been defined as the coincidental occurrence of chest pain, chest discomfort, dyspnea, faintness, nausea, vomiting, syncope, pruritus, urticaria, hypotension, diaphoresis, pallor, palpitations and bradycardia with conditions associated with mast cell activation including allergic, hypersensitivity, anaphylactic or anaphylactoid episodes. The cause of the above symptomatology has been attributed to Inflammatory mediators released via activation of mast cell and other interrelated and interacting inflammatory cells such as eosinophils, macrophages and T-lymphocytes. The culprit inflammatory mediators include histamine, neutral proteases, arachidonic acid products, platelet activating factor and a variety of cytokines and chemokines released during the activation process (29-31). In Kounis 
hypersensitivity-associated thrombotic syndrome, platelets are activated via the high-affinity and low-affinity $\operatorname{IgE}$ hypersensitivity receptors FC $\gamma \mathrm{RI}, \mathrm{FC} \gamma \mathrm{RII}, \mathrm{FC} \varepsilon \mathrm{RI}$ and FCERII. These receptors are activated by mediators released from the so-called "allergic unit" of eosinophils and mast cells. Interestingly, the same mediators have been found to be increased in acute coronary syndromes of non-allergic etiology and a potential common pathway between these has been proposed (32).

There are three variants of Kounis syndrome, the type I variant that represents a manifestation of endothelial dysfunction or microvascular angina and manifests as coronary artery spasm which could progress to acute myocardial infarction (33), the type II variant that manifests in patients with culprit but quiescent pre-existing atheromatous disease as either coronary artery spasm or coronary artery spasm together with plaque erosion or rupture leading to acute myocardial infarction (34) and the type III variant that manifests in patients with coronary artery stent thrombosis with thrombus infiltrated by eosinophils and mast cells and/ or when histological examination of coronary intima media and adventitia adjacent to stent is infiltrated by eosinophils or mast cells (35). A sub-type of Kounis syndrome with repeated episodes of stent thrombosis in the same stented area, at different periods has been also proposed (36).

In the medical literature, there are some surprising and unexpected reports according to which patients with stent implantation, who have developed hypersensitivity reactions elsewhere from other causes, have suffered contemporarily in-stent thrombosis. For example, allergic reactions from propyphenazone (37), contrast material (38), insect stings (39) and snake bites (40) were accompanied by in-stent thrombosis denoting that stents constitute the area of possible mast cell and platelet activation in order to cause Kounis syndrome. An astonishing event is that even an allergic reaction to clopidogrel (41), the drug that is given to prevent stent thrombosis, itself has induced stent thrombosis (42)! However, others (43) have emphasized the role of stent malapposition and under-expansion as prominent mechanisms for early stent thrombosis and have greatly recommended the use of intravascular imaging in order to achieve the optimal stent expansion, and to minimize large stent malapposition.

Therefore, the new efforts should be concentrated and be focused on the pathophysiology of stent thrombosis and discovering short lasting scaffolds and non-allergenic polymers in order to avoid hypersensitivity inflammation and stent thrombosis.

\section{The bioresorbable scaffolds}

The metallic scaffolds used in the bare metal and drug eluting stents counteract the two main events that can occur and progress in a set frame of time, namely coronary dissection during angiography and coronary artery restenosis. Since the majority of dissection and restenotic events occur within the first 6 months (44) and the most feared thrombotic complications of the permanent stents occur very late (beyond 1 year after implantation), the question which arises is: has any clear function a permanent stent prosthesis to be in place beyond this initial period?

One of the main reasons to develop a temporary scaffold is the short-term need for a stent and the potential longterm complications of metal scaffolds (45). Furthermore, limitations of the metallic scaffolds such as restenosis of a metallic stent that has been used to treat restenosis, abnormal vasoconstriction in response to acetylcholine and exercise distally to the deployed metallic stent, inability to perform coronary artery bypass grafting in metal-laden arteries, permanent jailing of side branches ostium by metallic stenting of bifurcations, late lumen loss, delayed endothelialization, persistent inflammation and finally hypersensitivity inflammation have paved the way for development of a third type of stents the so-called bioresorbable or bioabsorbable stents (3).

Indeed, the first bioabsorbable stent was developed at Duke University, USA and was implanted in animals (46). In this prototype stent, a polymer made of poly-L-lactide could withstand up to $1,000 \mathrm{mmHg}$ of crush pressure and was almost completely degraded by 9 months, while the Palmaz-Schatz stent can withstand a pressure of 300 to $500 \mathrm{mmHg}$ and keep its radial strength for 1 month. The previously tried bioabsorbable substances such as polyglycolic acid, polycaprolactone, poly(hydroxybutyratehydroxyvalerate), and polyorthoester have been abandoned today due to their inflammatory reactions.

Currently, bioresorbable stents come in a polymeric form while the bioabsorbable stents come in a metallic form. In the polymeric form, the most ubiquitous type of polymer is poly-L-lactic-acid polymer that is found in many medical devices, including resorbable sutures, orthopedic implants and soft-tissue implants. The metallic form of stents consists of either magnesium-based or iron-based alloys (47). These metals are alloyed with calcium, zinc and manganese as they are well tolerated in the human body. The magnesium variety has low thrombogenic action, low magnesium release in plasma and is not detectable under 
Table 1 Potential advantages and disadvantages of bioresorbable stents

\begin{tabular}{|c|c|}
\hline The advantages & The disadvantages \\
\hline $\begin{array}{l}\text { Addresses physician's and patient's desires to avoid a } \\
\text { permanent implant }\end{array}$ & $\begin{array}{l}\text { Higher early rates of scaffold thrombosis and target vessel-related } \\
\text { myocardial infarction }\end{array}$ \\
\hline $\begin{array}{l}\text { Allows treatment of in-stent restenosis without permanent } \\
\text { additional metal layer }\end{array}$ & Intraluminal scaffold dismantling \\
\hline $\begin{array}{l}\text { Facilitation of the return of vessel vasomotion-Facilitation of } \\
\text { noninvasive imaging follow-up without artifacts }\end{array}$ & Reduced deformability \\
\hline Future interventions in vessels with previous stenting & Reduced ductibility \\
\hline Future surgery in vessels with previous stenting & Some devices require cold storage and specific deployment techniques \\
\hline \multicolumn{2}{|l|}{ Reduction in the amount of dual antiplatelet therapy } \\
\hline \multicolumn{2}{|l|}{ Restoring late bypass surgery options } \\
\hline Unjailing of covered side branches & \\
\hline
\end{tabular}

magnetic resonance imaging or computed tomography that translated into the absence of artefacts' appearance (48). The alloying of Fe with other metals is necessary to alter its ferromagnetism which can reduce magnetic resonance imaging compatibility (49).

Many bioresorbable and bioabsorbable stents have a degradation time between 12 to 36 months. However, since these scaffolds are required to last from 6 to 12 months in order to allow the healing process to take place, thereafter the presence of the stent cannot provide any beneficial effect (44).

Therefore, bioresorbable and bioabsorbable stents have also polymers, metals and eluted drugs which have advantages and disadvantages that physicians should be aware of.

\section{Bioresorbable and bioabsorbable stent advantages, disadvantages, foreign body reaction and hypersensitivity}

In two recent papers published in Fournal of Thoracic Disease, the authors stated: in the first (50), "There is no convincing evidence that the bypothetical advantages of bioresorbable stents are or will be of any benefit to patients. More definitive evidence will only be available in about 5 to 7 years. Until then, the "optimistic" will continue to use it and the 'sceptic' will wait".
In the second (51) "Bioresorbable vascular scaffolds represent a disruptive technology that has caused a new evolution in interventional cardiology. Bioresorbable stents appear to be particularly appealing in patients presenting with an acute myocardial infarction. The available evidence on the value of bioresorbable stent implantation in this challenging scenario is very promising but still limited".

Indeed, bioresorbable and bioabsorbable stents have a lot advantages over the previous types of stents but have also many limitations (Table 1).

Recent reports have demonstrated that bioresorbable scaffold components can induce local foreign body reactions and hypersensitivity reactions. Upon stent implantation several proteins such as albumin, fibronectin, fibrinogen, and complement are being adsorbed on the surface of the implant. Following the initial tissue trauma, blood-implant interactions take place and lead to the activation of the complement system. This triggers the body's innate immune system, which leads to white blood cells infiltration (primarily neutrophils and monocytes) at the implantation site and to tissue edema. Neutrophils are the primary inflammatory cell type for the first 2 days following stent implantation, at which point they subside and macrophages, differentiated from recruited monocytes, become predominant.

The implant is recognized by macrophages as foreign substance due to protein adsorption on its surface, and the 
continuous presence of the implant results in macrophage differentiation and fusion into foreign body giant cells (52). The presence of macrophages and foreign body giant cells has been used as a marker for the foreign body reaction, even though their role has not been elucidated. On a molecular level, acute inflammation is characterized by increased levels of pro-inflammatory cytokines, such as IL-4, IL-8, and TNF (53). Such cytokines are excreted by neutrophils and macrophages and in the case of hypersensitivity are secreted by eosinophils and mast cells. These cytokines play an important role in inflammation regulation. During the final part of the foreign body reaction, collagen fibers are deposited around the implant and ultimately contract to form a dense, acellular, fibrous capsule (54).

Specifically, during poly-L-lactic-acid (L-lactic-coglycolic acid) degradation, acidic degradation products such as lactic and glycolic acid accumulate and decrease the $\mathrm{pH}$ in the surrounding tissue. This can trigger inflammatory and foreign body reactions in vivo $(55,56)$. Indeed, local foreign-body reactions (57), synovitis (58) especially in orthopedics and hypersensitivity reactions (59) have been associated with the use of poly (D,L-lactic-co-glycolic) acid. The systemic hypersensitivity reactions to poly (D,L-lacticco-glycolic) acid screws used in orthopedics have been proven by positive skin tests and necessitated to remove the screw (59).

Recent reports and trials have shown that a poly (D, L-lactic-co-glycolic) acid polymer scaffold is associated with daunting stent thrombosis. Emerging concerns exist regarding biocompatibility issues related to poly (D,L-lacticco-glycolic) acid degradation products after implantation (60) making this material no longer biologically inert.

Subacute stent thromboses involving bioresorbable stents in the real-world are rising rapidly. Indeed, Absorb bioabsorbable scaffold thromboses are appearing recently, especially in the real world, making this complication an alarming problem $(61,62)$. In a recent study $(63)$ contacted in 10 European countries, which included 1,189 patients who underwent percutaneous coronary intervention with one or more bioresorbable stents, the annualized rate of target lesion failure defined as the combination of cardiac death, target vessel myocardial infarction, or clinically driven target lesion revascularization was $10.1 \%$. The cumulative incidence of definite/probable scaffold thrombosis was $1.5 \%$ at 30 days and $2.1 \%$ at 6 months, with 16 of 23 cases occurring within 30 days. It was concluded that, in real world, the rates of early and midterm scaffold thrombosis, mostly clustered within 30 days, were not negligible. Another trial (64), that compared the MiStent bioabsorbable polymer sirolimuseluting stent with zotarolimus-drug eluting stent, showed superiority in the primary efficacy endpoint of 9-month mean late lumen loss for absorbable polymer sirolimuseluting stent compared to zotarolimus-eluting stent. However, in this trial, the 9-month stent thrombosis rate as defined by the Academic Research Consortium was $0.9 \%$ in 117 patients with absorbable polymer sirolimus-eluting stent and $1.7 \%$ in 60 patients with zotarolimus-eluting stent. Since it is not known whether bioabsorbable scaffold thrombosis is a time-limited complication, the problem might increase if events continue to occur over time with this kind of stents too.

Therefore, it seems that the prevention of vessel restenosis, vessel constriction, vessel remodeling, vessel inflammation, foreign body reaction acute, early late and very late stent thrombosis, hypersensitivity reaction, the Kounis syndrome is still far ahead.

\section{Conclusions}

Plain balloon angioplasty, metal stents, first and second generation drug-eluting stents bioabsorbable and bioresorbable scaffolds have offered diachronically a great advance in efforts to fight against coronary artery disease and have enriched our medical armamentarium. The general plea today $(50,51,62,65,66)$ is that further studies are required to gain a better understanding on advantages and limitations of bioresorbable and bioabsorbable stents as well as on the incidence and etiology of the feared stent thrombosis in real-world practice. This will enable physicians to prevent such daunting consequences. We have had already suggested (67) that the FDA recommendations (68) for coronary stent implantation should be applied also to bioresorbable scaffolds. These recommendations stated clearly that careful history of hypersensitivity reactions with monitoring of inflammatory mediators as well as lymphocyte transformation studies to detect material hypersensitivity must be undertaken before implantation of such devices.

Fortunately, on the $5^{\text {th }}$ of July 2016 the FDA in a press release and with an approval letter (69) approved the Absorb GT1 ${ }^{\text {TM }}$ Bioresorbable Vascular Scaffold (BVS) System-P150023 (Abbott Vascular in Santa Clara, California, USA) with the following suggestions and contraindications that the research and clinical community should be aware of: the Absorb GT1 BVS is contraindicated 
for patients who have a known hypersensitivity or allergy to everolimus, materials used in the device, such as poly (L-lactide), poly (D,L-lactide), contrast media, aspirin, antiplatelet agents or platinum.

It must be pointed out that, the eluted everolimus substance from Absorb stent has been already associated with the development of hypersensitivity pneumonitis (70), atopic dermatitis (71) and generalized (72) as well as lingual angioedema (73).

\section{Acknowledgements}

None.

\section{Footnote}

Conflicts of Interest: The authors have no conflicts of interest to declare.

\section{References}

1. Nabel EG, Braunwald E. A tale of coronary artery disease and myocardial infarction. N Engl J Med 2012;366:54-63.

2. Gruentzig A. Results from coronary angioplasty and implications for the future. Am Heart J 1982;103:779-83.

3. Brie D, Penson P, Serban MC, et al. Bioresorbable scaffold - A magic bullet for the treatment of coronary artery disease? Int J Cardiol 2016;215:47-59.

4. Kounis NG, Mazarakis A, Tsigkas G, et al. Kounis syndrome: a new twist on an old disease Future Cardiol 2011;7:805-24.

5. Rensing BJ, Vos J, Smits PC, Foley DP, et al. Coronary restenosis elimination with a sirolimus eluting stent; first European human experience with 6-month angiographic and intravascular ultrasonic follow-up, Eur Heart J 2001;22:2125-30

6. Kounis NG, Hahalis G, Theoharides TC. Coronary stents, hypersensitivity reactions, and the Kounis syndrome. J Interv Cardiol 2007;20:314-23.

7. Abizaid A, Costa JR Jr. New drug-eluting stents: an overview on biodegradable and polymer-free nextgeneration stent systems. Circ Cardiovasc Interv 2010;3:384-93

8. Kounis NG. Drug-eluting coronary-artery stents. N Engl J Med 2013;368:1558.

9. Kounis NG, Soufras GD. Coronary stent thrombosis: beware of an allergic reaction and of Kounis syndrome. Indian Heart J 2014;66:153-5.
10. Finn AV, Vorpahl $M$, Ladich $E$, et al Future directions in stenting. Expert Rev Cardiovasc Ther 2010;8:1-6.

11. Holmes DR Jr, Kereiakes DJ, Garg S, et al. Stent thrombosis. J Am Coll Cardiol 2010; 56:1357-65.

12. Heestermans AA, Van Werkum JW, Zwart B, et al. Acute and subacute stent thrombosis after primary PCI for ST-segment elevation myocardial infarction: incidence, predictors and clinical outcome. J Thromb Haemost 2010;8:2385-93.

13. Blich M, Zeidan-Shwiri T, Petcherski S, et al. Incidence, predictors and outcome of drug-eluting stent thrombosis in real-world practice. J Invasive Cardiol 2010;22:461-4.

14. Rzeszutko L, Depukat R, Dudek D. Biodegradable vascular scaffold ABSORB BVS ${ }^{\mathrm{TM}}$ - scientific evidence and methods of implantation. Postepy Kardiol Interwencyjnej 2013;9:22-30.

15. Bil J, Gil RJ. Bioresorbable vascular scaffolds-what does the future bring? J Thorac Dis 2016;8:E741-5.

16. Kereiakes DJ, Onuma Y, Serruys PW, et al. Bioresorbable Vascular Scaffolds for Coronary Revascularization. Circulation 2016;134:168-82.

17. Mehta SR, Yusuf S. Short- and long-term oral antiplatelet therapy in acute coronary syndromes and percutaneous coronary intervention. J Am Coll Cardiol 2003;41:79S-88S.

18. Shah BH, Lashari I, Rana S, et al. Synergistic interaction of adrenaline and histamine in human platelet aggregation is mediated through activation of phospholipase, map kinase and cyclo-oxygenase pathways. Pharmacol Res 2000;42:479-83.

19. Cargill DI, Cohen DS, Van Valen RG, et al. Aggregation, release and desensitization induced in platelets from five species by platelet activating factor (PAF). Thromb Haemost 1983;49:204-7.

20. McManus LM, Morley CA, Levine SP, et al. Platelet activating factor (PAF) induces release of platelet factor 4 (PF4) in vitro and during IgE anaphylaxis in the rabbit. J Immunol 1979;123:2835-41.

21. Henson PM. Activation of rabbit platelets by platelet activating factor derived from IgE-sensitized basophils. Characteristics of the aggregation and its dissociation from secretion. J Clin Invest 1977;60:481-90.

22. Hasegawa S, Pawankar R, Suzuki K, et al. Functional expression of the high affinity receptor for $\mathrm{IgE}$ (FcepsilonRI) in human platelets and its intracellular expression in human megakaryocytes. Blood 1999;93:2543-51.

23. Nosál R, Drábiková K, Jancinová V, et al Antiplatelet and antiphagocyte activity of H1-antihistamines. Inflamm Res 
2005;54:S19-20.

24. Petríková $M$, Jancinová V, Nosál R, et al. H(1)antihistamines and activated blood platelets. Inflamm Res 2006;55:S51-S52.

25. Almpanis GC, Tsigkas GG, Koutsojannis C, et al. Nickel allergy, Kounis syndrome and intracardiac metal devices. Int J Cardiol 2010;145:364-5.

26. Galli SJ, Tsai M, Piliponsky AM. The developement of allergic inflammation. Nature 2008;454:445-54.

27. Kounis NG, Goudevenos JA. Everolimus-eluting versus paclitaxel-eluting stents. Lancet 2010;375:1161; author reply $1161-2$..

28. Kounis NG, Zavras GM. Histamine-induced coronary artery spasm: the concept of allergic angina. Br J Clin Pract 1991;45:121-8.

29. Kounis GN, Hahalis G, Soufras GD, et al. Kounis syndrome and simultaneous multivessel acute coronary syndromes after successful drug-eluting stent implantation. Int J Cardiol 2008;127:146-8.

30. Baldomà N, Cosmen CR, Galinski SF, et al. Serum tryptase levels in acute coronary syndromes with ST elevation. Int J Cardiol 2009;131:403-4.

31. Ilhan E, Guvenc TS, Poyraz E, et al. Kounis Syndrome secondary to cefuroxime axetil use in an asthmatic patient. Int J Cardiol 2009;137:e67-9.

32. Kounis NG, Kouni SN, Koutsojannis CM. Myocardial infarction after aspirin treatment, and Kounis syndrome. J R Soc Med 2005;98:296.

33. Kounis NG. Kounis syndrome (allergic angina and allergic myocardial infarction): A natural paradigm? Int J Cardiol 2006;110:7-14.

34. Nikolaidis LA, Kounis NG, Grandman AH. Allergic angina and allergic myocardial infarction: a new twist on an old syndrome. Can J Cardiol 2002;18:508-11.

35. Biteker M. A new classification of Kounis syndrome. Int J Cardiol 2010;145:553.

36. Tsigkas G, Chouchoulis K, Theodoropoulos K, et al. Allergic reaction reveals a non-lethal late stent thrombosis. A new subtype of Kounis syndrome? Int J Cardiol 2011;149:281-2.

37. Patanè S, Marte F, Di Bella G, et al. Acute myocardial infarction and Kounis syndrome. Int J Cardiol 2009; 134:e45-6.

38. Kogias JS, Papadakis EX, Tsatiris CG, et al. Kounis syndrome: a manifestation of drug-eluting stent thrombosis associated with allergic reaction to contrast material. Int J Cardiol 2010;139:206-9.

39. Greif M, Pohl T, Oversohl N, et al. Acute stent thrombosis in a sirolimus eluting stent after wasp sting causing acute myocardial infarction: a case report. Cases J 2009;2:7800.

40. Satish R, Kanchan R, Yashawant R, et al. Acute MI in a stented patient following snake bite-possibility of stent thrombosis e a case report. Indian Heart J 2013;65:327-30.

41. Karabay CY, Can MM, Tanboga IH, et al. Recurrent acute stent thrombosis due to allergic reaction secondary to clopidogrel therapy. Am J Ther 2011;18:e119-e122.

42. Liping Z, Bin H, Qiming F. An extraordinary case associated with an allergic reaction to clopidogrel: Coronary artery spasm or Kounis Syndrome? Heart Lung Circ 2015;24:e180-e183.

43. Lee SY, Hong MK. Mechanisms of stent thrombosis: insights from optical coherence tomography. J Thorac Dis 2016;8:E460-2.

44. Colombo A, Karvouni E. Biodegradable stents: "fulfilling the mission and stepping away". Circulation 2000;102:371-3.

45. Zidar J, Lincoff A, Stack R. Biodegradable stents. In: Topol EJ. editor. Textbook of Interventional Cardiology. 2nd ed. Philadelphia: Saunders, 1994:787-802.

46. Stack RS, Califf RM, Phillips HR, et al. Interventional cardiac catheterizat:1988;62:3F-24F.

47. Peuster M, Wohlsein P, Brugmann M, et al. A novel approach to temporary stenting: degradable cardiovascular stents produced from corrodible metal-results 6-18 months after implantation into New Zealand white rabbits. Heart 2001;86:563-9.

48. Brown DA, Lee EW, Loh CT, et al. A new wave in treatment of vascular occlusive disease: biodegradable stents-clinical experience and scientific principles. J Vasc Interv Radiol 2009; 20:315-24.

49. Gundogan B, Tan A, Farhatnia Y, et al. Bioabsorbable stent quo vadis: a case for nano-theranostics. Theranostics 2014; 4:514-33.

50. Arroyo D, Cook S, Puricel S. Bioresorbable vascular scaffolds-time to vanish? J Thorac Dis 2016;8:E431-6.

51. Alfonso F, Cuesta J, Bastante T, et al. Bioresorbable vascular scaffolds in patients with acute myocardial infarction: a new step forward to optimized reperfusion? J Thorac Dis 2016;8:E417-23.

52. Yang J, Jao B, McNally AK, et al. In vivo quantitative and qualitative assessment of foreign body giant cell formation on biomaterials in mice deficient in natural killer lymphocyte subsets, mast cells, or the interleukin-4 receptor alpha and in severe combined immunodeficient mice. J Biomed Mater Res A 2014;102:2017-23.

53. Kastellorizios M, Tipnis N, Burgess DJ. Foreign body reaction to subcutaneous implants. Adv Exp Med Biol 
2015;865:93-108.

54. Anderson JM, Rodriguez A, Chang DT. Foreign body reaction to biomaterials. Semin Immunol 2008;20:86-100.

55. Yoon SJ, Kim SH, Ha HJ, et al. Reduction of inflammatory reaction of poly (D, L-lacticco-glycolic acid) using demineralized bone particles. Tissue Eng Part A 2008;14:539-47.

56. Lendlein A, Langer R. Biodegradable, elastic shapememory polymers for potential biomedical applications. Science 2002;296:1673-6.

57. Böstman OM, Pihlajamäki HK. Adverse tissue reactions to bioabsorbable fixation devices. Clin Orthop Relat Res 2000;371:216-27.

58. Freehill MQ, Harms DJ, Huber SM, et al. Poly-L-lactic acid tack synovitis after arthroscopic stabilization of the shoulder. Am J Sports Med 2003;31:643-7.

59. Mastrokalos DS, Paessler HH. Allergic reaction to biodegradable interference poly-L-lactic acid screws after anterior cruciate ligament reconstruction with bonepatellar tendon-bone graft. Arthroscopy 2008;24:732-3.

60. Ji W, Yang F, Seyednejad H, et al. Biocompatibility and degradation characteristics of PLGA-based electrospun nanofibrous scaffolds with nanoapatite incorporation. Biomaterials 2012;33:6604-14.

61. Miyazaki T, Panoulas VF, Sato K, et al. Bioresorbable vascular scaffolds for left main lesions: a novel strategy to overcome limitations. Int J Cardiol 2014;175:e11-e13.

62. Ho HH, Er Ching M, Ong PJ, et al. Subacute bioresorbable vascular scaffold thrombosis: a report of 2 cases. Heart Vessels 2015;30:545-8.

63. Capodanno D, Gori T, Nef H, et al. Percutaneous coronary intervention with everolimus-eluting bioresorbable vascular scaffolds in routine clinical practice: early and midterm outcomes from the European multicentre GHOST-EU registry. EuroIntervention

Cite this article as: Kounis NG, Koniari I, Roumeliotis A, Tsigas G, Soufras G, Grapsas N, Davlouros P, Hahalis G. Thrombotic responses to coronary stents, bioresorbable scaffolds and the Kounis hypersensitivity-associated acute thrombotic syndrome. J Thorac Dis 2017;9(4):1155-1164. doi: $10.21037 /$ jtd.2017.03.134
2015;10:1144-53.

64. Wijns W, Vrolix M, Verheye S, et al. Randomised study of a bioabsorbable polymer-coated sirolimus-eluting stent: results of the DESSOLVE II trial. EuroIntervention. EuroIntervention 2015;10:1383-90.

65. Lutter C, Joner M. Bioresorbable drug eluting scaffoldsare bioresorbable stents ready for today's clinical practice? J Thorac Dis 2016;8:1050-2.

66. Costopoulos C, Naganuma T, Latib A, et al. Looking into the future with bioresorbable vascular scaffolds. Expert Rev Cardiovasc Ther 2013;11:1407-16.

67. Kounis NG, Soufras GD, Tsigkas G, et al. Bioabsorbable stent thrombosis Quo Vadis: is Kounis syndrome still present? Int J Cardiol 2014;176:305-6.

68. Johnson GC. XIENCE ${ }^{\mathrm{TM}} \mathrm{V}$ everolimus eluting coronary stent system and PROMUS everolimus eluting coronary stent system (2008) (EECSS). Food and Drug Administration, Silver Spring. Accessed: 2 June 2014. Available online: http://www.accessdata.fda.gov

69. Prove letter of Absorb GT1 $1^{\mathrm{TM}}$ Bioresorbable Vascular Scaffold (BVS) System. Available online: http://www. accessdata.fda.gov/cdrh_docs/pdf15/P150023a.pdf

70. Sibertin-Blanc C, Norguet E, DulucM, et al. Severe hypersensitivity pneumonitis associated with everolimus therapy for neuroendocrine tumour: a case report. BMC Res Notes 2013;6:471.

71. Van Velsen SG, Haeck IM, Bruijnzeel-Koomen CA. Severe atopic dermatitis treated with everolimus. J Dermatolog Treat 2009;20:365-7.

72. FuchsU, Zittermann A, Berthold HK, et al. Immunosuppressive therapy with everolimus can be associated with potentially life-threatening lingual angioedema. Transplantation 2005;79:981-3.

73. Mackenzie M, Wood LA. Lingual angioedema associated with everolimus. Acta Oncol 2010;49:107-9. 